\title{
CARLOS POTENCIANO REYES, MD (1940 - 2020) Little-Known but Significant Pioneer
}

Generoso T. Abes, MD, MPH

Consultants and more senior coresident physicians at the Philippine General Hospital (PGH) would call him "Caloy." Hardly would I hear anybody (including our ENT department secretary) address him as Dr. Reyes. This was not because he was not a respected faculty member. Rather, he was everybody's friend and he probably preferred to be addressed by his nickname.

Dr. Carlos P. Reyes was a tall, friendly guy, easily recognizable while walking through the short PGH corridor stretching from the old ENT Ward (Ward 3) to the old ENT operating room (OR) called Floor 15, later designated as the PGH Nursing Office. He would almost always be holding either an expensive photography camera, electronic gadget, ENT OR instrument, or car magazines - suggesting his varied

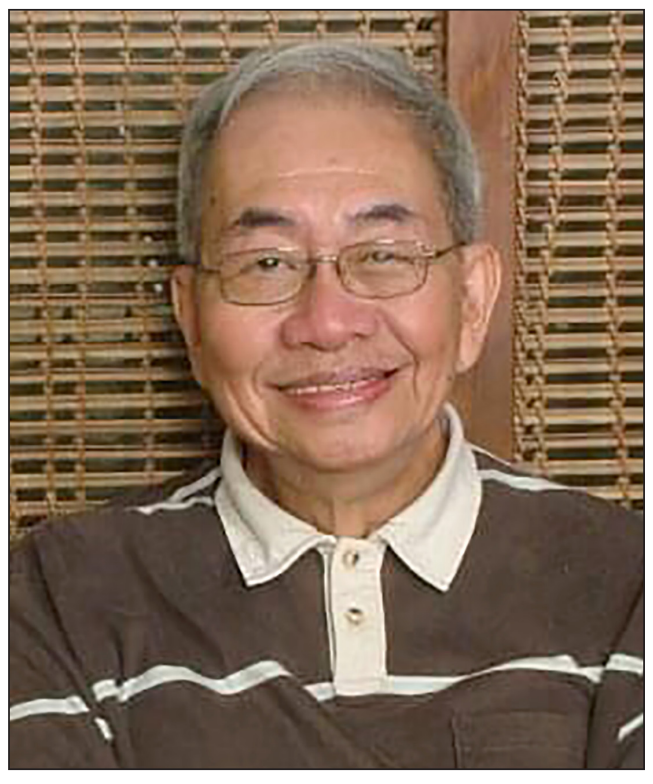

and arrive at the complex diagnosis.

Dr. Caloy was our mentor at the time when refinements in tympanoplasty and mastoidectomy aroused the excitement and imagination of budding otologists worldwide. Whereas canal down mastoidectomy was the usual norm to safely remove common mastoid pathology like cholesteatoma, Dr. Caloy introduced the concept of intact canal wall mastoidectomy that avoids or mitigates recurrent postoperative cleaning of the mastoid bone. The period was also the dawn of neuro-otology when Dr. William House popularized the transmastoid approach for acoustic neuroma and the endolymphatic mastoid shunt as treatment for Meniere's disease. In order to teach us the anatomical and surgical principles of performing interests aside from having good knowledge of Otolaryngology, particularly Otology. He would usually stop and chat with an acquaintance about his new medical or non-medical interests.

I first met Dr. Caloy when I was the first year resident assigned to the Otology section. He would call me "Ging" while presenting the ear patients at the outpatient department (OPD) Ear Clinic, only to learn later that he would address all unfamiliar persons by that name. He was kind, helpful and very understanding. Equipped with ample information in Otology he gathered from postgraduate studies abroad, he would selflessly share these with the residents in order to sharpen our diagnostic acumen. He would instruct us to rely on concise yet complete clinical examination, involving audiologic evaluation tools and meager radiologic information in considering differential diagnoses. He was quite willing to assist us in our learning processes, particularly on how to distinguish middle ear from inner ear disorders, and cochlear versus retrocochlear diseases. Since we did not have any audiologist at that time, he admonished us to carry out the needed audiometric evaluations on our ear patients ourselves in order to learn both the techniques of the procedures and their limitations. Hence, after the OPD clinic we would not only perform routine pure tone and speech audiometric tests but also special examinations like the Bekesy test, short increment sensitivity index (SISI) test, alternate binaural loudness balance (ABLB) test and the test for tone decay. We would then discuss the test results during our next ear clinic and we would listen and be amazed at how Dr. Caloy would integrate the information these procedures, Dr. Caloy set up the first temporal bone dissection laboratory in the country at the mezzanine above the ENT conference room. He would offer the course to all ENT residents-in-training and consultants nationwide. He practically revolutionized the method of otologic surgery by requiring ENT surgeons to practice doing ear surgery in the temporal bone dissection lab prior to performing ear surgeries in the operating room. In addition, he advocated the use of the operating microscope and dental drills in place of the old bone gouges, chisels and bone ronguers. His ideas were later adopted by other ENT training institutions as we see today. The requirement that every ENT resident must undergo temporal bone dissection in the course of his training obviously stemmed from the efforts of Dr. Caloy. Many senior ENT consultants who are still with us today were former students of Dr. Caloy in his temporal bone lab.

Unfortunately, before finishing my residency training, $\mathrm{Dr}$ Caloy expeditiously left the PGH ENT department for unknown reasons. He then set up his private clinic in Quezon City and later joined the ENT department of University of Santo Tomas.

Reflecting on the significant yet probably unknown achievements of Dr. Caloy toward the advancement of otology and neuro-otology in our country, I realize how blessed I was to be one of his students during that brief period when he was still with us at UP-PGH.

With our profound gratitude Sir, we will always remember you. 